\title{
Contribution of Meat Inspection to the surveillance of poultry health and welfare in the European Union
}

\author{
A. HUNEAU-SALAÜN ${ }^{1 *}, K$. D. C. STÄRK ${ }^{2,3}$, A. MATEUS ${ }^{2,3}$, C. LUPO ${ }^{4}$, \\ A. LINDBERG ${ }^{5}$ AND S. LE BOUQUIN-LENEVEU ${ }^{1}$ \\ ${ }^{1}$ ANSES, Ploufragan-Plouzané Laboratory, Ploufragan, France \\ ${ }^{2}$ SAFOSO Inc., Bern, Switzerland \\ ${ }^{3}$ Royal Veterinary College, Hertfordshire, UK \\ ${ }^{4}$ IFREMER, SG2M-LGPMM, La Tremblade, France \\ ${ }^{5}$ National Veterinary Institute, Uppsala, Sweden
}

Received 3 June 2014; Final revision 18 August 2014; Accepted 19 November 2014; first published online 18 December 2014

\section{SUMMARY}

In the European Union, Meat Inspection (MI) aims to protect public health by ensuring that minimal hazardous material enters in the food chain. It also contributes to the detection and monitoring of animal diseases and welfare problems but its utility for animal surveillance has been assessed partially for some diseases only. Using the example of poultry production, we propose a complete assessment of MI as a health surveillance system. MI allows a long-term syndromic surveillance of poultry health but its contribution is lowered by a lack of data standardization, analysis and reporting. In addition, the probability of case detection for 20 diseases and welfare conditions was quantified using a scenario tree modelling approach, with input data based on literature and expert opinion. The sensitivity of MI appeared to be very high to detect most of the conditions studied because MI is performed at batch level and applied to a high number of birds per batch.

Key words: Animal welfare, disease surveillance, Meat Inspection, poultry.

\section{INTRODUCTION}

From the past to the present: why does Meat Inspection (MI) need to evolve?

MI is a control process commonly described as a set of tasks performed at slaughterhouses and sometimes at farms to ensure that animals entering the food chain comply with the legal hygiene requirements for human consumption. The major aim of MI is therefore to protect the public from hazards, such as

\footnotetext{
* Author for correspondence: Dr A. Huneau-Salaün, ANSES, BP53, 22440 Ploufragan, France.

(Email: adeline.huneau@anses.fr)
}

infectious agents, that could be transmitted or carried by meat (contamination).

The increasing burden of foodborne illnesses and the rapid changes in food production and food exchanges throughout the world led the Food and Agriculture Organization and the World Health Organization to propose guidelines for strengthening food control systems [1]. Taking into account this international context, a new European legislation, relying on the White Paper on Food Safety published in 2000, has been developed. It aims to base food control systems on an integrated 'farm-to-fork' approach and on a risk analysis process. The White Paper was the stepping stone for the three Hygiene Regulations known as the Hygiene Package, that deal with all 
foods and that cover the entire food chain [2]. In the Hygiene Package, Regulation 854/2004 lays down specific rules for the organization of official controls on animal products [3].

The first conclusions on the application of this regulation drawn by the chief veterinary officers of the European Member States in 2008 showed that a modernization of sanitary inspection in slaughterhouses was needed to fully exploit benefits from a risk-based approach. Consequently, the European Commission [4] mandated the European Food Safety Authority (EFSA) to evaluate the capacity of current MI to assess the fitness of meat for human consumption and, if needed, to propose modifications to ensure an appropriate level of public health protection (Mandate 1005) [5]; the questions had to be considered separately for the main animal production systems in Europe, including poultry. As the main public health hazards in poultry products could not be detected by the current visual MI [6], proposed changes in MI procedures were expected to be important. In addition to the protection of public health, MI also contributes to animal health and welfare surveillance by detecting and monitoring disease syndromes and welfare problems that are not reported at the farm level. The EFSA panel on Animal Health and Animal Welfare (AHAW) was mandated to assess the potential consequences on animal health and welfare surveillance of the changes in the current MI system proposed by the other EFSA panels.

The objective of our paper was to present findings of this assessment and to demonstrate how this evaluation evolved from an empirical and practical experience to a global and quantitative assessment. This paper focuses only on poultry species but reports on other species have been published on the EFSA website (http://www.efsa.europa.eu, topic Meat Inspection). First, a literature review will describe the past experiences demonstrating the contribution of the current MI procedures to poultry health surveillance. Second, the methodology and the main results will be shown. Elements dealing with the impact of the modernization of MI on poultry health surveillance can be found elsewhere [6].

\section{SURVEILLANCE OF ANIMAL HEALTH AND WELFARE DURING THE CURRENT MI PROCEDURE}

The current MI procedure in the European Union is described for all species in Annex I of Regulation
854/2004 [7] with special dispositions for poultry species in Section IV, Chapter V. The epidemiological unit of interest in MI is a batch of poultry, i.e. poultry reared on the same holding and sent to slaughter in a single transport. The MI for poultry comprises three inspection tasks carried out under the supervision of the Official Veterinarian (OV). MI tasks can be delegated to official auxiliaries operating under the supervision of the $\mathrm{OV}$ (Annex I, Section III, Chapter III and part A). In poultry and lagomorph abattoirs, these auxiliaries may be from the slaughterhouse staff provided that the inspection staff acts independently from the production staff and they receive appropriate training provided by the official veterinary authorities.

\section{Food chain information}

The first step in MI is devoted to checking and analysing food chain information (FCI), i.e. relevant information on animals' identification and on animals' health transmitted from the holding of provenance. Required FCI is described in Annex II, Section III of Regulation 853/2004 [7]; most of the Member States collect harmonized FCI at national level via a standardized declaration form. FCI has to be transmitted to the $\mathrm{OV}$ at least $24 \mathrm{~h}$ before slaughtering, when the ante-mortem inspection is performed at the abattoir. If the birds have been inspected at the farm of origin, FCI can be provided before unloading the batch in the slaughterhouse. FCI is based on declarations of farmers and food business operators (FBO). The reliability of FCI might be questionable. However Lupo et al. [8] concluded that FCI transmitted to slaughterhouses was concordant with on-farm observations collected by independent investigators. FCI analysis is a direct application of the risk-based approach because results from FCI have to be taken into account to adapt the thoroughness of the inspection process accordingly to the health status of the batch. The study of Lupo et al. [9] showed that FCI was relevant to identify batches of broilers with a high risk of sanitary condemnation, demonstrating the usefulness of FCI for a risk-based MI. Various measures can be taken in response to the estimated risk of condemnation shown by a batch of poultry, e.g. slowing down the slaughter line speed to allow in-depth inspection. In France, an experimental programme is presently conducted to define a standardized frame of application of the risk-based inspection and to estimate its practicality under commercial conditions [10]. 


\section{Ante-mortem inspection (AMI)}

The second inspection task is the AMI which takes place at slaughterhouse in most of the Member States but can be also performed on farm for poultry species. AMI mainly aims to detect any sign indicating that animal welfare has been compromised during handling and transport or that animals are affected by conditions likely to adversely affect animal or human health. In particular, stress caused by loading and transport may enhance the expression of clinical signs in animals suffering from a disease at incubation or subclinical stages. There are 2-3 points of control for AMI [11]; inspection in crates, inspection after unloading and inspection after stunning. Only a sample of crates is inspected before unloading but all birds are individually observed during the manual shackling. AMI is the key stage for monitoring welfare conditions relative to handling and transport of poultry (e.g. dead on arrival, thermal comfort during transport) but Regulation 854/ 2004 also states that special attention should be observed during AMI for the detection of diseases on the OIE list [12]. For instance, avian botulism can only be detected during the inspection of live birds due to its pathognomonic clinical signs (flaccid paralysis of the neck, wings and/or legs) as no visible lesion can be detected during post-mortem inspection (PMI).

\section{Post-mortem inspection}

The third task is the PMI of the whole plucked carcass, the viscera and the carcass after evisceration (including the body cavity). PMI is designed to detect and withdraw from the food chain carcasses showing grossly identifiable abnormalities that may affect their safety or wholesomeness; special attention should be also placed on the detection of zoonotic diseases and of diseases classified in the OIE list [12]. By contrast to previous inspection tasks that are mostly done at batch level, PMI is performed at the individual level implying that all carcasses are to be inspected. PMI leads to condemnation of carcasses or parts of them that are judged to be unfit for human consumption, based on a visual inspection. Reasons for carcass condemnation are not explicitly described in Regulation 854/2004 but possible origins of unfit meat are exhaustively listed. Condemnation for poultry carcasses is based on visual macroscopic criteria that are rarely pathognomonic. As an example, the most frequent reasons for condemnation in broiler and turkey broiler batches in France are emaciation and congestion, which are generic terms concordant with a large spectrum of diseases and conditions [13, 14]. A few infectious or parasitic diseases may lead to pathognomonic lesions enabling a direct diagnosis during PMI. For instance, histomoniasis (Histomonas meleagridis) sometimes leads to characteristic round lesions on liver that could be detected during manual evisceration [15] but birds affected at such an advanced stage of the disease are normally unfit for slaughter. Avian tuberculosis (Mycobacterium avium) is a chronic infection with a protracted course that may go unnoticed at the farm but typical tubercular granulomata can be easily detected on the spleen and liver during PMI [16]. Nevertheless, a reason for condemnation is generally given with no inference on the aetiology of the lesions. As an example, in a study on carcasses condemned for skin lesions, Fallavena et al. [17] concluded that cutaneous macroscopic changes as observed at PMI were not specific and did not allow accurate identification of skin diseases.

\section{SPECIFIC CONTRIBUTION OF CURRENT MI TO POULTRY HEALTH AND WELFARE SURVEILLANCE}

\section{A two-way information flow: an opportunity for poultry health surveillance}

Regulation 854/2004 requires transmission of the results from MI to the FBOs and to the primary producer when the detected problems may be related to rearing conditions. This disposition establishes the principle of a two-way information flow: from the farm to the slaughterhouse by FCI, and from the abattoir to the farm by transmission of MI results. There are some practical examples of benefits from feedback transmission of MI observations. A pilot study reported by Ansong-Danquah et al. [18] was conducted in a Canadian abattoir during 5 years in 1980s, with a systematic feedback of MI results to farmers and to broiler companies. During the first 2 years, lesions caused by Marek's disease were the primary cause of carcass condemnations, underlining insufficient vaccination coverage of the broiler population. Vaccination programmes were therefore reinforced by the broiler companies and condemnations for lesions due to Marek's disease were no longer relevant during the final 3 years of the experiment.

\section{Integration of welfare surveillance}

The recent evolution of the assessment of animal welfare towards the monitoring of animal-based welfare 
indicators [19] gives a new dimension to PMI. As demonstrated in the Welfare Quality project [20], animalbased welfare-outcome indicators related to body condition in poultry can be more easily and more accurately monitored during PMI than on farm. This is the case for injuries, haematomas, scratches, foot-pad dermatitis, hock burns and breast blisters, which are more visible on shackled and plucked carcasses. Ascites characterized by an accumulation of liquid in the body cavity is also better detected during PMI than on farm or at AMI. These conditions provide information on welfare during handling and transport but also on welfare during rearing, since most of the indicators are significantly associated with on-farm factors [21, 22]. The Swedish Broiler Welfare Programme demonstrates that the regulation of broiler density during rearing, based on the prevalence of foot-pad dermatitis observed during PMI, can reduce the incidence of this problem [23, 24].

The implementation of Directive 2007/43/EC on broiler protection will generalize the use of PMI for collection of animal-based welfare indicators; results from PMI become one of the key indicators to allow derogation to the maximum stocking density during rearing.

\section{Concrete examples of MI contribution to poultry health surveillance}

Despite the fact that the main aim of MI is to protect public health from foodborne hazards, it also allows the monitoring of animal health and welfare. This system can both contribute to the detection of cases of an emerging or re-emerging animal disease and to the monitoring of the prevalence of endemic diseases and welfare conditions. Although these contributions to animal health surveillance are potentially high, there are few examples in the literature clearly demonstrating the value of MI in this context (Table 1). Most of these studies rely on an in-depth PMI, sometimes completed by histological and bacteriological analysis. Furthermore, outputs of these studies are rarely analysed in any other way than the economic impact of condemnations for producers and FBOs. Discussions proposed by the authors on the contribution of MI to animal health surveillance are summarized in Table 1.

A relevant experience of the MI contribution to poultry health surveillance is the emergence of cellulitis in North America. At the end of 1990s, a sharp increase in carcass condemnations was detected in Canadian poultry abattoirs [25], due to a new kind of skin lesion classified as cellulitis. Examination of condemned carcasses of broilers and turkeys enabled the precise description of this condition, which was not visible on animals at farm nor at AMI as it is a subclinical syndrome [26]. A monitoring programme of the percentage of carcass condemnations for cellulitis was consequently started in federal abattoirs. This programme allowed quantification of the increasing incidence of cellulitis during the following years [27]. Observations during PMI were also used to classify batches according to their level of condemnation for cellulitis; this classification was the basis for an analytical epidemiological survey to identify risk factors for cellulitis on poultry farms [28].

\section{ASSESSING THE CONTRIBUTION OF MI TO POULTRY HEALTH AND WELFARE SURVEILLANCE IN EUROPE}

\section{Qualitative assessment of the contribution of MI to poultry health surveillance}

Surveillance is defined as a systematic ongoing collection, aggregation, and analysis of data and the timely transmission of information to the risk manager in order to take mitigation measures [29]. MI can be considered as a component of a syndromic surveillance performed at slaughter level: FCI, clinical signs and gross lesions are used to monitor various health hazards, without further diagnosis. Table 2 provides a list of criteria to assess the quality of a surveillance system, adapted from Salman et al. [30], and its application to the current MI system in poultry. Most of the quality criteria can be assessed from a complete description of MI procedures, as carried out by Löhren [11], but estimation of sensitivity and positive predictive value could only be obtained by experiment [31] or by modelling using methods such as latent classes [32, 33] or decision-tree scenarios.

Despite this lack of available data on performance, quality assessment was used to produce a short Strength-Weakness-Opportunity-Threat (SWOT) analysis of MI as a surveillance component (Table 3) [34]. MI is now a long-standing and well-accepted surveillance component in Europe. One of its major strengths is its high representativeness: mortality rates of poultry during rearing are relatively low in the European Union, implying that most of the birds entering production are sent to the abattoir and submitted to MI. MI may be considered as an early-warning surveillance as any modification in the 
Table 1. Examples of studies using Meat Inspection (MI) for monitoring health and welfare in poultry in Europe, North America, South America, Middle East and Asia. Classification of the studies according to their objectives: 'case report' (description of a new condition), 'prevalence' (assessment of condition prevalence and its temporal evolution), 'aetiology' (identification of the aetiology of a condition) and 'risk factors' (identification of factors associated with the occurrence of a condition)

\begin{tabular}{|c|c|c|c|c|c|}
\hline Country & Objective & Condition & $\begin{array}{l}\text { MI } \\
\text { procedure }\end{array}$ & $\begin{array}{l}\text { Discussion on the interest of MI in animal } \\
\text { health surveillance }\end{array}$ & Source \\
\hline UK & Prevalence & $\begin{array}{l}\text { Causes of } \\
\text { condemnation }\end{array}$ & Routine & & [43] \\
\hline UK & $\begin{array}{l}\text { Prevalence } \\
\text { Risk factors }\end{array}$ & $\begin{array}{l}\text { Causes of } \\
\text { condemnation }\end{array}$ & Routine & $\begin{array}{l}\text { Difficulties in classification of causes of } \\
\text { condemnation: lack of concordance between } \\
\text { abattoirs }\end{array}$ & [44] \\
\hline France & $\begin{array}{l}\text { Prevalence } \\
\text { Risk factors }\end{array}$ & $\begin{array}{l}\text { Causes of } \\
\text { condemnation }\end{array}$ & Routine & & {$[13,45]$} \\
\hline France & $\begin{array}{l}\text { Prevalence } \\
\text { Risk factors }\end{array}$ & $\begin{array}{l}\text { Causes of } \\
\text { condemnation }\end{array}$ & Routine & & [14] \\
\hline France & Risk factors & Skin lesions & Routine & $\begin{array}{l}\text { Broiler welfare during rearing can be assessed } \\
\text { based on lesions observed during MI }\end{array}$ & {$[22]$} \\
\hline Norway & $\begin{array}{l}\text { Prevalence } \\
\text { Aetiology }\end{array}$ & Hepatic lesions & Routine & $\begin{array}{l}\text { Suggest the use of the rate of condemnation for } \\
\text { hepatic lesions as an indicator for the } \\
\text { surveillance of necrotic enteritis in broilers }\end{array}$ & [46] \\
\hline Ireland & $\begin{array}{l}\text { Prevalence } \\
\text { Risk factors }\end{array}$ & Bruises & Reinforced & & [47] \\
\hline Denmark & $\begin{array}{l}\text { Prevalence } \\
\text { Risk factors }\end{array}$ & Pododermatitis & Routine & $\begin{array}{l}\text { Variation between abattoirs due to subjectivity } \\
\text { of the inspection }\end{array}$ & {$[48]$} \\
\hline Denmark & Aetiology & Dead on arrival & Reinforced & $\begin{array}{l}\text { 'Dead-on-arrival' birds as observed during } \\
\text { AMI are an accurate indicator of welfare } \\
\text { conditions during pre-slaughter handling }\end{array}$ & [49] \\
\hline Netherlands & Case report & $\begin{array}{l}\text { Lesions due to } \\
\text { Ornithobacterium }\end{array}$ & Routine & $\begin{array}{l}\text { MI as an alarm system: increase in } \\
\text { condemnations for aerosacculitis. Only mild } \\
\text { symptoms at farm, not reported }\end{array}$ & {$[50]$} \\
\hline Netherlands & Prevalence & $\begin{array}{l}\text { Lesions due to } \\
\text { Ornithobacterium }\end{array}$ & Reinforced & & {$[51]$} \\
\hline Lithuania & Prevalence & $\begin{array}{l}\text { Causes of } \\
\text { condemnation }\end{array}$ & Routine & $\begin{array}{l}\text { Insufficient feedback to farmers provided by } \\
\text { MI services: data on carcass condemnations } \\
\text { are not used to implement preventive } \\
\text { measures at farm level }\end{array}$ & [52] \\
\hline Bulgaria & Aetiology & Nephropathy & Routine & $\begin{array}{l}\text { Condemnations for nephropathies led to the } \\
\text { identification of animal feed contamination } \\
\text { by mycotoxins }\end{array}$ & [53] \\
\hline Poland & Prevalence & $\begin{array}{l}\text { Causes of } \\
\text { condemnation }\end{array}$ & Routine & & [54] \\
\hline Canada & Case report & Cellulitis & Routine & & [55] \\
\hline Canada & Prevalence & Cellulitis & Routine & $\begin{array}{l}\text { Subjectivity in condemnations, variation } \\
\text { between abattoirs in inspection decisions }\end{array}$ & $\begin{array}{l}{[56]} \\
{[27]}\end{array}$ \\
\hline Canada & Prevalence & Cellulitis & Routine & $\begin{array}{l}\text { Interest on MI in detection of the emerging } \\
\text { condition and its subsequent monitoring }\end{array}$ & [25] \\
\hline Canada & Prevalence & Ascitis & Routine & & [55] \\
\hline Canada & Prevalence & $\begin{array}{l}\text { Causes of } \\
\text { condemnation }\end{array}$ & Routine & & [57] \\
\hline Canada & Prevalence & $\begin{array}{l}\text { Causes of } \\
\text { condemnation }\end{array}$ & Reinforced & & {$[58]$} \\
\hline Canada & Aetiology & Hepatic lesions & Reinforced & & [59] \\
\hline Canada & Risk factors & Cyanosis & Routine & & [60] \\
\hline Canada & Risk factors & Cellulitis & Reinforced & & [28] \\
\hline
\end{tabular}


Table 1 (cont.)

\begin{tabular}{|c|c|c|c|c|c|}
\hline Country & Objective & Condition & $\begin{array}{l}\text { MI } \\
\text { procedure }\end{array}$ & $\begin{array}{l}\text { Discussion on the interest of MI in animal } \\
\text { health surveillance }\end{array}$ & Source \\
\hline USA & $\begin{array}{l}\text { Prevalence } \\
\text { Aetiology } \\
\text { Risk factors }\end{array}$ & $\begin{array}{l}\text { Squamous cell } \\
\text { carcinoma }\end{array}$ & Routine & & {$[61]$} \\
\hline USA & Etiology & Septicaemia & Reinforced & $\begin{array}{l}\text { Experimental assay to assess the association } \\
\text { between macroscopic lesions noticeable } \\
\text { during PMI and causative agents }\end{array}$ & {$[31]$} \\
\hline Brazil & Case report & $\begin{array}{l}\text { Dorsal cranial } \\
\text { myopathy }\end{array}$ & Routine & $\begin{array}{l}\text { Report of a new form of myopathy on heavy } \\
\text { broilers, only detectable at PMI }\end{array}$ & {$[62]$} \\
\hline Brazil & Prevalence & Ascitis & Routine & & [63] \\
\hline Brazil & Prevalence & $\begin{array}{l}\text { Aerosacculites } \\
\text { Traumatic lesions }\end{array}$ & Routine & $\begin{array}{l}\text { Suggest the use of data from MI by the industry } \\
\text { to evaluate specific programmes and identify } \\
\text { areas of improvements }\end{array}$ & {$[64]$} \\
\hline Brazil & Prevalence & $\begin{array}{l}\text { Causes of } \\
\text { condemnation }\end{array}$ & Routine & & {$[65,66]$} \\
\hline Brazil & Aetiology & Skin lesion syndrome & Reinforced & $\begin{array}{l}\text { Macroscopic lesions are not specific, no } \\
\text { inference on aetiological cause is possible }\end{array}$ & {$[17]$} \\
\hline Brazil & Aetiology & Aerosacculites & Reinforced & & {$[67]$} \\
\hline $\begin{array}{l}\text { Saudi } \\
\text { Arabia }\end{array}$ & Case report & Hemorrhages & Routine & $\begin{array}{l}\text { MI as an alarm system: increase of } \\
\text { condemnation of subcutaneous haemorrhages } \\
\text { not detected at farm }\end{array}$ & [68] \\
\hline Iran & Prevalence & $\begin{array}{l}\text { Causes of } \\
\text { condemnation }\end{array}$ & Routine & & [69] \\
\hline Japan & Case report & Endocarditis & Routine & $\begin{array}{l}\text { Report of broiler infection by Streptococcus } \\
\text { gallolyticus: subclinical but visible lesions at } \\
\text { PMI }\end{array}$ & [70] \\
\hline
\end{tabular}

AMI, Ante-mortem inspection; PMI, Post-mortem inspection.

health state of animals could be detected in a timely manner. However emerging or re-emerging diseases are expected to be detected before slaughter (clinical surveillance at farm) and MI is rather the ultimate component of a passive (or reactive) surveillance system, which raises the alarm when the others components fail. The special case of MI in poultry is that the inspection is performed at both batch and bird levels. The global approach at batch level is of interest in animal health surveillance: warning thresholds could be set up for main health indicators and standardized measures proposed in response to the alerts. The use of the MI system for the surveillance of animal health does not add supplementary costs to the expenses already incurred for public health protection; it is therefore an inexpensive way to monitor animal health. Regarding weaknesses, there are basically several technical factors (e.g. speed of the line and lighting) that may interfere with the detection of health problems. The results of MI may also depend on staff experience. A systematic use of AMI observations and condemnation results for health surveillance would require the centralization of results in a harmonized frame of collection and specific staff devoted to results analysis. MI is not an 'enhanced passive' surveillance component [29], as there is no general and active supervision of MI results in terms of animal health and welfare. In addition to technical constraints and difficulties in data centralization, flexibility of $\mathrm{MI}$ is rather low because its general frame is fixed by European and national regulations: any modification to the procedure needs time, staff formation and sometimes financial resources in order for it to be implemented at a national level. The risk-based approach adopted with the Hygiene Package is an opportunity for the optimization of MI as a surveillance component. However the risk-based surveillance only targets the needs for public health protection: the new dispositions may constitute the main threat to the contribution of MI to animal health surveillance. 
Table 2. Qualitative assessment of Meat Inspection (MI) as a surveillance component for health and welfare surveillance in poultry in the European Union (adapted from Salman et al. [30])

\begin{tabular}{|c|c|c|}
\hline Parameter & Definition & Application to MI \\
\hline Usefulness & $\begin{array}{l}\text { Contribution to the prevention and } \\
\text { control of diseases }\end{array}$ & Potentially high. Examples given for poultry \\
\hline Simplicity & Ease of operating & $\begin{array}{l}\text { Need training of operators and technical constraints are } \\
\text { high }\end{array}$ \\
\hline Flexibility & $\begin{array}{l}\text { Ability of the system to adapt to changing } \\
\text { information needs of operating } \\
\text { conditions }\end{array}$ & $\begin{array}{l}\text { Low: high number of operators. Modification needs to be } \\
\text { applied in a harmonized way and may require legislation } \\
\text { changes }\end{array}$ \\
\hline Quality of data & Completeness and validity & $\begin{array}{l}\text { Potentially high for completeness } \\
\text { Validity: harmonization of data collection in the } \\
\text { regulations but some subjectivity remains in MI decisions }\end{array}$ \\
\hline Acceptability & Willingness of operators to participate & $\begin{array}{l}\text { High: MI is mandatory and it is of high economic } \\
\text { importance for food business operators to produce meat } \\
\text { fit for human consumption }\end{array}$ \\
\hline Sensitivity & $\begin{array}{l}\text { Ability to detect a case or to detect a } \\
\text { change in prevalence }\end{array}$ & To be evaluated in the present paper \\
\hline $\begin{array}{l}\text { Positive predictive } \\
\text { value }\end{array}$ & $\begin{array}{l}\text { Proportion of reported cases that are } \\
\text { actually related to the event under } \\
\text { surveillance }\end{array}$ & $\begin{array}{l}\text { Low in term of identification of aetiological cause } \\
\text { High for syndromes despite some subjectivity in the } \\
\text { assessment }\end{array}$ \\
\hline Representativeness & Population coverage & Complete for animals fit for transport \\
\hline Timeliness & The time between steps in surveillance & $\begin{array}{l}\text { Short time between detection and report to primary } \\
\text { producer (upward flow of information) and/or report to } \\
\text { veterinary authorities. However, feedback is not always } \\
\text { done }\end{array}$ \\
\hline \multirow[t]{2}{*}{ Stability } & $\begin{array}{l}\text { Reliability: ability to collect, manage and } \\
\text { provide data without failure }\end{array}$ & $\begin{array}{l}\text { Reliability: potentially high if a data collection system is } \\
\text { set up }\end{array}$ \\
\hline & $\begin{array}{l}\text { Availability: ability to be operational } \\
\text { when it is needed }\end{array}$ & Availability: high because MI system is perennial system \\
\hline
\end{tabular}

\section{Quantitative assessment of the contribution of MI to poultry health surveillance}

Methodology. The assessment of sensitivity, i.e. the probability of detecting cases, remains the key element in evaluating the performance of MI as a health surveillance system [35]. We used quantitative decisiontree scenario models to evaluate the sensitivity of MI as an animal surveillance system, parameterized with data from the literature if available or by expert opinion. The approach is described in more detail by Stärk \& Nevel [34]. Briefly, the EFSA AHAW panel defined a list of 20 poultry diseases and welfare conditions to be addressed; the prioritization of diseases took into account the relevance of their surveillance at the slaughterhouse, their epidemiologialc characteristics (epizootic or enzootic diseases) and their regulatory and/or economic importance. A bibliographical review was performed to gather data on the prevalence of diseases and welfare conditions at flock level and at the European level and on risk factors associated with these conditions. The review was completed by elicitation of expert opinion to complete gaps in knowledge identified. The elicitation was based on a modified Delphi method as described by Stärk et al. [36] and the questionnaires used for elicitation are available from the authors upon request.

For each disease or welfare condition, the most affected poultry (species, age and type of production, i.e. egg, meat or breeder) was identified and typical and mild cases described by the experts (Fig. 1). A typical case as seen during MI was defined by a set of symptoms and lesions that are likely to be observed in more than two thirds of birds affected by the given condition and presented for slaughter. A mild case was characterized by more subtle signs than a typical case but was still detectable during MI; it was assumed to be less frequent than a typical case. In a second step of elicitation, experts were asked to provide estimates on the prevalence of affected batches arriving for slaughter, the proportion of typical and mild cases in an affected batch and the probability of detection of 
Table 3. Strength-Weakness-Opportunity-Threat (SWOT) analysis of Meat Inspection (MI) as a surveillance system of animal health and welfare surveillance

\begin{tabular}{ll}
\hline \hline Strengths & Well-established and well-accepted: FBOs have economic interests in MI \\
& High coverage of targeted population \\
& Continuous monitoring: basis to draw reliable trends \\
& Capacity to detect emerging problems \\
& Two-way information flows \\
& Animal health and welfare surveillance is not the first objective of MI \\
& Only suitable for problems leading to macroscopic abnormalities \\
& Animal are fit for transport: detection of milder cases than in farm surveillance \\
Weaknesses & No specific case definition \\
& Lack of standardization despite efforts of harmonization \\
& High technical constraints \\
& Lack of flexibility: input-based design, fixed by regulations \\
& Data are not centralized and analysed at national or EU levels \\
& Implementation of welfare regulations in EU: abattoir is the best place for \\
assessment of animal-based welfare indicators & Relying on a risk-based approach enabling optimization of cost/benefit ratio \\
Opportunities & Automatization of MI process \\
& Evolution of MI to cover new public health hazards: reallocation of resources \\
Threats & Delegation of visual MI to FBOs \\
\hline \hline
\end{tabular}

FBO, Food business operator; EU, European Union.

a typical case during each step of the MI procedure. The final outcome of the expert elicitation was an estimate (most likely \pm range) of the probability of detection under the current MI procedure of a typical case for each of the 20 diseases or welfare conditions.

Next, the value of MI as a surveillance system was assessed, using two scenario tree models: the 'freedom of disease' approach for epizootic diseases [highly pathogen avian influenza (HPAI) and Newcastle disease] and the 'detection fraction' approach for other enzootic diseases and welfare conditions [37]. The 'freedom of disease' approach measures the ability of a surveillance system to detect one or more infected birds and/or batch of birds if the frequency of the disease is higher than a designed prevalence in the monitored population [38]. This method then evaluates the capacity of a surveillance system to detect an emerging or re-emerging disease and to give an 'alert signal'. In the 'detection fraction' approach, the value of a surveillance system is assessed by the proportion of cases of the disease detected by the surveillance; this approach is adapted to monitor prevalence of an enzootic disease. In both approaches, the models yield a probability of detection that could be interpreted as the sensitivity of the surveillance system. Consolidated estimates collected during expert elicitation for AMI and PMI were used as input, together with estimates of proportions of case types likely to be presented at the abattoir. The output was estimated by translation of the consolidated estimates into BetaPert distributions, and by using Monte-Carlo simulation (10 000 iterations). Each step of the model represents a node of a tree, and is run in the sequence shown in Figure 1. The most likely and 5th and 95th percentiles of the output distributions of AMI, PMI and the whole inspection process were derived for each disease and condition.

\section{Sensitivity of MI for poultry health and welfare surveillance}

The sensitivity of MI for detection of a 'typical' case was estimated as high for most of the diseases and conditions studied (Table 4). This high sensitivity has to be examined taking into account some methodological limitations. The methodological development was an on-going process and was not fully consolidated when poultry was considered (one of the first species studied along with pigs). The first limitation was linked to the assumption that the probabilities of detection of abnormalities at each inspection step were independent, leading to a possible underestimation of the detection sensitivity for diseases demonstrating signs detectable at a small number of inspection points, e.g. for botulism or 'dead on arrival'. In addition, in a risk-based inspection, each inspection step has to be adapted taking into account the results of the previous steps, implying a dependence of the task results. Nevertheless, the 


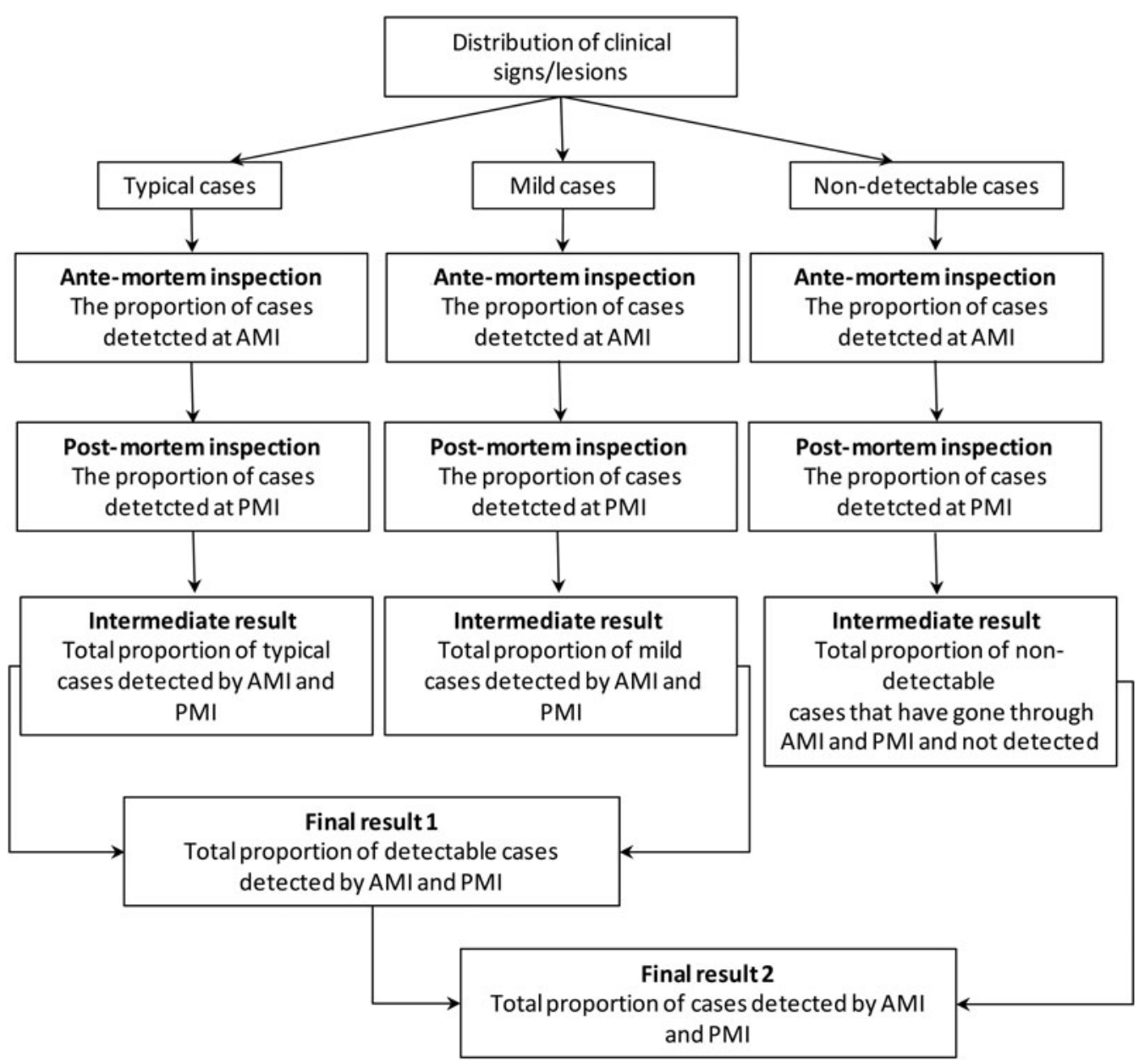

Fig. 1. Flow diagram of the scenario tree model, with the arrows indicating the order that each step occurs, i.e. node of the tree is calculated. AMI, Ante-mortem inspection; PMI, post-mortem inspection.

sensitivity estimations given separately for each inspection step by the experts [37] suggested that the evaluation of FCI contributed more than the crate inspection to the detection of abnormalities during AMI. During PMI, visual inspection of organs and, to a lesser extent, of the body cavity were considered the most sensitive tasks for disease detection whereas observation of the whole carcass and the feet contributed the most to the detection of welfare problems. Another methodological difficulty was related to the organization of MI for poultry both at batch level (AMI) and at bird level (PMI). The sensitivity of detection of an affected batch (i.e. a batch with a least one affected bird) depended on the sensitivity of detection at bird level and also on the number of animals submitted to MI. Since the size of a poultry batch is generally high (several thousands of birds), the sensitivity of detection at batch level was particularly high for all diseases and conditions. It is therefore expected that the inspection of a large number of animals will always be a very effective way of detecting diseases, even though the sensitivity of detection at the bird level is low.

\section{Relative contribution of MI to the global animal health surveillance system}

In addition to the evaluation of sensitivity of MI to detect diseases and welfare problems, we assessed the relative contribution of MI to animal surveillance compared to other surveillance components existing in the European Union. One epizootic disease (avian influenza; AI), three enzootic diseases (aspergillosis, colisepticaemia, infectious bursal disease; IBD) and one welfare problem (ascites) were considered. For $\mathrm{AI}$, a conventional scenario tree model for freedom of disease was used considering two surveillance components other than MI: clinical surveillance at farm [39] and serological surveillance [40]. The estimated sensitivities at batch level (for a common batch size 
Table 4. Probabilities of case detection (mode) of ante- and post-mortem inspection procedures at individual bird level ( $5 \%$ and $95 \%$ percentiles) for 20 diseases and conditions

\begin{tabular}{|c|c|c|}
\hline Diseases and conditions & Ante-mortem inspection & Post-mortem inspection \\
\hline \multicolumn{3}{|l|}{ Epizootic } \\
\hline Highly pathogenic avian influenza & $0.98(0.95-0.995)$ & $1 \cdot 00(1 \cdot 00-1 \cdot 00)$ \\
\hline Newcastle disease & $0.92(0.88-0.96)$ & $1 \cdot 00(1 \cdot 00-1 \cdot 00)$ \\
\hline \multicolumn{3}{|l|}{ Endemic diseases } \\
\hline Coliform celullitis (gangrenous celullitis) & $0 \cdot 78(0 \cdot 55-0 \cdot 89)$ & $1 \cdot 00(1 \cdot 00-1 \cdot 00)$ \\
\hline Mycoplasma gallisepticum infection & $0.92(0.86-0.97)$ & $0.98(0.97-0.99)$ \\
\hline Colisepticaemia & $0.81(0.53-0.99)$ & $1 \cdot 00(1 \cdot 00-1 \cdot 00)$ \\
\hline Botulism & $0.98(0.96-0.99)$ & $0 \cdot 00(0 \cdot 00-0 \cdot 00)$ \\
\hline Necrotic enteritis and hepatic disease & $0.95(0 \cdot 89-1 \cdot 00)$ & $1 \cdot 00(0 \cdot 99-1 \cdot 00)$ \\
\hline Avian tuberculosis & $0.92(0.79-0.96)$ & $1 \cdot 00(1 \cdot 00-1 \cdot 00)$ \\
\hline Egg peritonitis & $0.62(0.47-0.74)$ & $1 \cdot 00(1 \cdot 00-1 \cdot 00)$ \\
\hline Duck plague & $0.99(0.97-1 \cdot 00)$ & $1 \cdot 00(1 \cdot 00-1 \cdot 00)$ \\
\hline Infectious bursal disease & $0.91(0.82-0.97)$ & $0 \cdot 80(0 \cdot 68-0 \cdot 91)$ \\
\hline Aspergillosis & $0.79(0.69-0.85)$ & $1 \cdot 00(0 \cdot 99-1 \cdot 00)$ \\
\hline Histomoniasis & $0.96(0.91-0.98)$ & $1 \cdot 00(1 \cdot 00-1 \cdot 00)$ \\
\hline \multicolumn{3}{|l|}{ Welfare conditions } \\
\hline Dead on arrival & $1 \cdot 00(0 \cdot 91-1 \cdot 00)$ & $0 \cdot 00(0 \cdot 00-0 \cdot 00)$ \\
\hline Thermal discomfort & $0.85(0.76-0.94)$ & $1 \cdot 00(0 \cdot 98-1 \cdot 00)$ \\
\hline Traumatic injuries & $0.99(0.97-1.00)$ & $1 \cdot 00(1 \cdot 00-1 \cdot 00)$ \\
\hline Pododermatitis & $0.74(0.57-0.82)$ & $0.80(0.64-0.87)$ \\
\hline Skin lesions & $0.85(0.74-0.93)$ & $1 \cdot 00(1 \cdot 00-1 \cdot 00)$ \\
\hline Tarsal dermatitis & $0.71(0.56-0 \cdot 86)$ & $1 \cdot 00(1 \cdot 00-1 \cdot 00)$ \\
\hline Ascites & $0.93(0.85-0.96)$ & $1 \cdot 00(1 \cdot 00-1 \cdot 00)$ \\
\hline
\end{tabular}

equal to 10000 birds) were very high and similar for the three surveillance components considered (Table 5). A scenario tree model has already been used to assess the sensitivity of an AI surveillance system in Canada [41] and in Catalonia [42]. In these studies, MI was not taken into account in the surveillance system thus its sensitivity was not estimated. This omission suggests that $\mathrm{MI}$ is not considered as a means of AI detection, despite that surveillance of OIE list A diseases is one of the MI objectives. Our results showed, however, that MI could be as sensitive as other passive or active components of the surveillance system. It might be worth considering it when evaluating the effectiveness of the overall surveillance system. The Spanish study considered clinical surveillance at farm as a component of the surveillance system; the probability of detecting a batch of broilers infected by HPAI was as high as we estimated in this project for AI in turkeys, but was considerably lower for low pathogenic avian influenza (LPAI). Such a distinction according to AI pathogenicity could not be made in our project because data on epidemiology of HPAI and LPAI are lacking at the European scale.

For the four other enzootic conditions, a tree model based on the 'detection fraction' approach was developed including MI and clinical surveillance as
Table 5. Estimated proportion of turkeys and turkey batches detected as true positives for avian influenza by different surveillance system components

\begin{tabular}{lll}
\hline \hline $\begin{array}{l}\text { Surveillance } \\
\text { system } \\
\text { component }\end{array}$ & $\begin{array}{l}\text { Proportion of true } \\
\text { positives detected } \\
\text { (per bird, animal } \\
\text { level) }\end{array}$ & $\begin{array}{l}\text { Proportion of true } \\
\text { positives detected } \\
\text { (per batch, 10 000 } \\
\text { birds) } \dagger\end{array}$ \\
\hline $\begin{array}{l}\text { Abattoir } \\
\text { inspection }\end{array}$ & $0 \cdot 0103$ & $1 \cdot 0$ \\
$\begin{array}{l}\text { Clinical } \\
\text { suspicion }\end{array}$ & 0.0017 & $1 \cdot 0$ \\
$\begin{array}{l}\text { Serology } \\
\text { Combined* }\end{array}$ & 0.0245 & $1 \cdot 0$ \\
\hline
\end{tabular}

* The combined value does not consider overlap between surveillance system components.

$\dagger$ Assumed between-flock prevalence $=0.096$, within-flock prevalence $=0 \cdot 283$.

surveillance components. The detection fraction for colisepticaemia and IBD was estimated to be very high for a batch of 10000 birds, both for clinical suspicion and MI (Table 6) because the within-flock prevalence at farm was estimated as high by expert opinion (more than $30 \%$ of infected birds) and the 
Table 6. Detection fraction at batch level (10000 birds) of selected endemic diseases/conditions by abattoir inspection and clinical suspicion and comparative detection performance with an assumed coverage of 100\%

\begin{tabular}{lllll}
\hline \hline & $\begin{array}{l}\text { Abattoir inspection, } \\
\text { SSC1 }\end{array}$ & $\begin{array}{l}\text { Clinical suspicion, } \\
\text { SSC2 }\end{array}$ & $\begin{array}{l}\text { Incremental benefit, SSC1 } \\
\text { over SSC2 }\end{array}$ & $\begin{array}{l}\text { Incremental benefit, SSC2 } \\
\text { over SSC1 }\end{array}$ \\
\hline $\begin{array}{l}\text { Aspergillosis } \\
\text { Colisepticaemia }\end{array}$ & 0.049 & $0 \cdot 001$ & $0 \cdot 049$ & $0 \cdot 001$ \\
$\begin{array}{l}\text { Infectious bursal } \\
\text { disease }\end{array}$ & $1 \cdot 0$ & $1 \cdot 0$ & $0 \cdot 0$ & $0 \cdot 0$ \\
Ascites & 0.849 & 0.962 & $0 \cdot 038$ & $0 \cdot 0$ \\
\hline \hline
\end{tabular}

SSC, Surveillance system component.

farmer's and veterinarian's awareness was also expected to be high for these diseases. The benefit of abattoir inspection over farm surveillance was therefore minimal. By contrast, the incremental benefit of MI surveillance over clinical surveillance turned out to be high for ascites. Expert opinion estimated the probability of detection by the farmer to be low $(<50 \%)$ for this condition: ascites cases are rare in a flock of broilers, occurring mainly at the end of the rearing period when farmers are not prone to ask for a veterinarian visit and the symptoms are usually general and unspecific. The probability of detection of ascites was estimated as very high during PMI, leading to a higher value of MI than clinical surveillance for detecting ascites. For aspergillosis in breeder turkeys, the benefit of MI was also higher than for clinical suspicion but the detected fraction remained very low. This was due to low between- and withinflock prevalences and a high proportion of mild cases, which are more difficult to detect.

\section{CONCLUSION}

Surveillance of poultry health during MI is an example of a syndromic surveillance, as in most of the cases, no inference can be made on the aetiological cause based on the clinical signs and lesions observed during slaughter. MI enables rapid collection of data on any health event but it does not contribute to earlywarning surveillance as it occurs at the last step of the production chain; MI is rather the ultimate component of a passive surveillance system. Nevertheless, the increased use of animal-based welfare indicators in the assessment of poultry welfare confers a new importance on MI, given that these indicators are more easily collected at slaughter than on farm. Despite that, there is a common agreement on its interest, concrete and quantified examples of the contribution of
MI to poultry health surveillance are lacking because surveillance data generated by MI are not harmonized at the European level and they are not systematically collected and analysed. However, some past examples show that the two-way information flow from the farm to the slaughterhouse (FCI) and from the slaughterhouse to the farm (MI information) could be effectively used to monitor and even enhance poultry health and welfare. The models proposed to quantify the sensitivity of current MI in the surveillance of both enzootic and epizootic diseases provide a tool which allows the assessment of the potential impact of a revised MI procedure on poultry health surveillance in Europe.

\section{ACKNOWLEDGEMENTS}

We acknowledge the contributions of the experts who participated in the expert elicitation exercise. We are also grateful to Mr Georgiev from the Animal Health and Welfare Unit of EFSA and to members of the working group appointed by EFSA to integrate this work to AHAW scientific opinions, particularly to Professor More. This work was supported by EFSA (service contract no. CT/EFSA/AHAW/2010/05).

\section{DECLARATION OF INTEREST}

None.

\section{REFERENCES}

1. FAO/OMS. Assuring Food Safety and Quality: Guidelines for Strengthening National Food Control Systems. FAO Food and Nutrition Paper No. 76, 2002, $84 \mathrm{pp}$.

2. Dwinger RH, et al. A brief overview of food hygiene legislation. Deutsche Tieraerztliche Wochenschrift 2007; 114: 294-298. 
3. FAO. Risk-based food inspection manual. Rome, Italy: Organisation Mondiale des Nations Unies pour l'alimentation et l'agriculture; 2008, 85 pp.

4. European Commission. Report from the Commission to the Council and the European Parliament on the experience gained from the application of the hygiene regulation (EC) No. 852/2004, (EC) No. 853/2004 and (EC) No. 854/2004 of the European Parliament and of the Council of 29 April 2004, 2009.

5. European Commission, Health and Consumers Directorate - General. Requests for a scientific opinion and technical assistance on the public health hazards to be covered by inspection of meat, 2010.

6. EFSA. Scientific Opinion on the public health hazards to be covered by inspection of meat (poultry). EFSA Journal 2012; 10: 2471.

7. Anon. Regulation (EC) No. 854/2004 of the European Parliament and the Council of 29 April 2004 laying down specific rules for the organisation of official controls on products of animal origin intended for human consumption. Official Journal of the European Union 2004; L 139: 206-320.

8. Lupo C. Appreciation of the risk of sanitary condemnation in poultry carcasses ar slaughterhouse based on food chain information: University of Rennes 1, 2009, $323 \mathrm{pp}$.

9. Lupo C, et al. Bayesian network as an aid for food chain information use for meat inspection. Preventive Veterinary Medicine 2013; 109: 25-36.

10. Allain V, et al. Health inspection at poultry slaughterhouses: indicators of tasks achievement for veterinary inspection missions. In: World Veterinary Poultry Association Congress. Nantes, France: ISPAIA, 2013, pp. 112.

11. Löhren U. Overview on current practices of poultry slaughtering and poultry meat inspection: supporting publications EN-298, 2012, 58 pp.

12. OIE. OIE-listed diseases, infections and infestations in force in 2014 (http://www.oie.int/en/animal-healthin-the-world/oie-listed-diseases-2014/). Paris, France: OIE. Accessed 12 May 2014.

13. Lupo C, et al. Postmortem condemnations of processed broiler chickens in western France. Veterinary Record 2008; 162: 709-713.

14. Lupo C, et al. Risk and indicators of condemnation of male turkey broilers in western France, February-July 2006. Preventive Veterinary Medicine 2010; 94: 240-250.

15. Grist A. Poultry Inspection, 2nd edn. Nottingham: Nottingham University Press, 2006, pp. 276.

16. Jordan FTW. Avian tuberculosis. In: Jordan FTW, ed. Poultry Diseases, 3rd edn. London: Baillère Tindall, 1990, pp. 68-73.

17. Fallavena LCB, et al. Diagnosis of skin lesions in condemned or downgraded carcasses - a microscopic and macroscopic study. Avian Pathology 2000; 29: $557-562$.

18. Ansong-Danquah J. A survey of carcass condemnation at a poultry abattoir and its application to disease management. Canadian Veterinary Journal 1987; 28: 53-56.
19. EFSA. Scientific opinion on the use of animal-based measures to assess welfare of broilers. EFSA Journal 2012; 10: 2774.

20. Welfare Quality. Welfare quality assessment protocol for poultry (broilers, laying hens). Lelystad, The Netherlands, 2009, 114 pp.

21. Gouveia KG, Vaz-Pires P, Martins da Costa P. Welfare assment of broilers through examination of haematomas, foot-pad dermatitis, scratches and breast blisters at processing. Animal Welfare 2009; 18: 43-48.

22. Allain $\mathbf{V}$, et al. Relations between different skin lesions measured at slaughterhouse in broiler chickens and between prevalence of these lesions and different rearing factors. British Poultry Science 2009; 50: 407-417.

23. Ekstrand C, et al. Prevalence and control of foot-pad dermatitis in broilers in Sweden. British Poultry Science 1998; 39: 318-324.

24. Berg C. Pododermatitis and hock burn in broiler chickens. In: Weeks CA, Butterworth A, eds. Measuring and Auditing Broiler Welfare. Wallingford: CABI, 2004, pp. 37-50.

25. Kumor LW, et al. Cellulitis in broiler chickens: epidemiological trends, meat hygiene, and possible human health implications. Avian Diseases 1998; 42: 285-291.

26. Olkowski AA, et al. Cellulitis lesions in commercial turkeys identified during processing. Veterinary Record 1999; 145: 228-229.

27. Saint-Hilaire $\mathbf{S}$, Sears W. Trends in cellulitis condemnations in the Ontario chicken industry between April 1998 and April 2001. Avian Diseases 2003; 47: 537-548.

28. Elfadil AA, Vaillancourt JP, Meek AH. Farm management risk factors associated with cellulitis in broiler chickens in southern Ontario. Avian Diseases 1996; 40: 699-706.

29. Hoinville LJ, et al. Proposed terms and concepts for describing and evaluating animal-health surveillance systems. Preventive Veterinary Medicine 2013; 112: 1-12.

30. Salman MD, Stärk KDC, Zepeda C. Quality assurance applied to animal disease surveillance systems. Revue Scientifique et Technique de l'Office International des Epizooties 2003; 22: 689.

31. Fisher ME, Trampel DW, Griffith RW. Post mortem detection of acute septicemia in broilers. Avian Diseases 1998; 42: 452-461.

32. Enoe $\mathbf{C}$, et al. The need for built-in validation of surveillance data so that changes in diagnostic performance of post-mortem meat inspection can be detected. Preventive Veterinary Medicine 2003; 57: 117-125.

33. Bonde M, et al. Evaluation of sensitivity and specificity of routine meat inspection of Danish slaughter pigs using latent class analysis. Preventive Veterinary Medicine 2010; 94: 163-169.

34. Stärk KDC, Nevel A. Strengths, weaknesses, opportunities and threats of the pig health monitoring systems used in England. Veterinary Record 2009; 165: 461-465.

35. Hathaway SC, Richards MS. Determination of the performance attributes of post-mortem meat inspection procedures. Preventive Veterinary Medicine 1993; 16: 119-131. 
36. Stärk KDC, et al. Strengths and weaknesses of meat inspection as a contribution to animal health and welfare surveillance. Food Control 2014; 39: 154-162.

37. COMISURV. External scientific report submitted to EFSA on the contribution of meat inspection to animal health surveillance in poultry, 2012, $131 \mathrm{pp}$.

38. Martin PAJ, Cameron AR, Greiner M. Demonstrating freedom from disease using a complex data sources 1 : a new methodology based on scenario trees. Preventive Veterinary Medicine 2007; 79: 71-97.

39. Anon. Commission Decision of 19 October 2005 laying down biosecurity measures to reduce the risk of transmission of highly pathogenic avian influenza caused by Influenza virus A subtype $\mathrm{H} 5 \mathrm{~N} 1$ from birds living in the wild to poultry and other captive birds and providing for an early detection system in areas at particular risk. Official Journal of the European Union 2005; L 274: 105 .

40. Anon. Commission Decision of 25 June 2010 on the implementation by Member States of surveillance programmes for avian inf luenza in poultry and wild birds (notified under document C(2010) 4190). Official Journal of the European Union 2010; L 166: 22.

41. Christensen $\mathbf{J}$, et al. A scenario tree model for the Canadian Notifiable Avian Influenza Surveillance System and its application to estimation of probability of freedom and sample size determination. Preventive Veterinary Medicine 2011; 99: 161-175.

42. Alba A, et al. Assessment of different surveillance systems for avian influenza in commercial poultry in Catalonia (North-Eastern Spain). Preventive Veterinary Medicine 2010; 97: 107-118.

43. Bremner AS. Post mortem condemnation returns from poultry slaughterhouses in England and Wales. Veterinary Record 1994; 135: 622-623.

44. Haslam SM, et al. Prevalence and factors associated with it, of birds dead on arrival at the slaughterhouse and other rejection conditions in broiler chickens. British Poultry Science 2008; 49: 685-696.

45. Lupo C, et al. Risk factors for sanitary condemnation in broiler chickens and their relative impact: application of an original multiblock approach. Epidemiology and Infection 2010; 138: 364-375.

46. Lovland A, Kaldhusdal M. Liver lesions seen at slaughter as an indicator of necrotic enteritis in broiler flocks. FEMS Immunology and Medical Microbiology 1999; 24: 345-351.

47. Mayes FJ. The incidence of bruising in broiler flocks. British Poultry Science 1980; 21: 505-9.

48. Kyvsgaard NC, et al. Temporal changes and risk factors for foo-pad dermatitis in Danish broilers. Poultry Science 2013; 92: 26-32.

49. Lund VP, et al. Pathological manifestations observed in dead-on-arrival broilers at a Danish abattoir. British Poultry Science 2013; 54: 430-440.

50. van Veen $\mathbf{L}$, et al. Increased condemnation of broilers associated with Ornithobacterium rhinotracheale. Veterinary Record 2000; 147: 422-423.
51. van Veen $\mathbf{L}$, et al. Diagnosis and incidence of Ornithobacterium rhinotracheale in commercial broiler chickens at slaughter. Veterinary Record 2005; 156: 315.

52. Januskeviciene G, et al. Analysis of pathologic lesions in the livestock and poultry slaughtered in the meat establishments of Lithuania. Veterinarija ir Zootechnika 2010; 52: 33-42.

53. Stoev SD, et al. Mycotoxic nephropathy in Bulgarian pigs and chickens: complex etiology and similarity to Balkan Endemic Nephropathy. Food Additives and Contaminants 2009; 27: 72-88.

54. Radkowski M, Uradzinski J, Szteyn J. The occurrence of infectious and parasitic diseases in poultry slaughtered in the district of Olsztyn, Poland, 1986-91. Avian Diseases 1996; 40: 285-289.

55. Olkowski AA, Kumor LW, Classen HL. Changing epidemiology of ascites in broiler chickens. Canadian Journal of Animal Science 1996; 76: 135-140.

56. Tessier M, et al. Cellulitis in broiler chickens: a one-year retrospective study in four Québec abattoirs. Avian Diseases 2001; 45: 191-194.

57. Bielby M. A review of broiler chicken condemnations in Western Canada in 1998. In: Proceedings of the Forty-eighth Western Poultry Disease Conference. Vancouver, Canada, 1999, pp. 7-8.

58. Herenda D, Jakel O. Poultry abattoir survey of carcass condemnation for standard, vegetarian, and free range chickens. Canadian Veterinary Journal 1994; 35: 293 296.

59. Hutchison TWS, Riddel C. A study of hepatic lesions in broiler chickens at processing plants in Saskatchewan. Canadian Veterinary Journal 1990; 31: 20-25.

60. Mallia JG, et al. Risk factors for abattoir condemnation of turkey carcasses due to cyanosis in Southern Ontario. Poultry Science 2000; 79: 831-837.

61. Weinstock D, et al. Histopathology and epidemiology of condemnations due to squamous cell carcinoma in broiler chickens in North Carolina. Avian Diseases 1995; 39: 676-686.

62. Zimmerman FC, et al. Downgrading of heavy broiler chicken carcasses due to myodegenration of the anterior latissimus dorsi: pathologic and epidemiologic studies. Avian Diseases 2012; 56: 418-421.

63. Jacobsen G, Flôres ML. Ascitic condemnations in broilers slaughtered under federal inspection between 2002 and 2006 in Rio Grande do Sul, Brazil. Cienca Rural 2008; 38: 1966-1971.

64. d'Arc Moretti L, et al. Time series evaluation of traumatic lesions and airsacculitis at one poultry abattoir in the state of Sao Paulo, Brazil (1996-2005). Preventive Veterinary Medicine 2010; 94: 23123-9.

65. Santana AP, et al. Causes of condemnation of carcasses from poultry in slaughterhouses located in state of Goias, Brazil. Cienca Rural 2008; 38: 2587-2592.

66. Paschoal EC, Otutumi LK, Silveira AP. Major reasons for condemnation in broiler slaughter in a slaughter house located in the northwest of Parana, Brazil. Arquivos de Ciencas Veterinarias e Zoologia 2013; 15: 93-97. 
67. Spanamberg A, et al. Aspergillus fumigatus from normal and condemned carcasses with airsacculitis in commercial poultry. Pesquisa Veterinaria Brasileira 2013; 33: 1071-1075.

68. Aboulela MA. CAV and broiler downgrading. Poultry International 1998, pp. 30-31.
69. Ansari-Lari M, Rezagholi M. Poultry abattoir survey of carcass condemnations in Fars province, southern Iran. Preventive Veterinary Medicine 2007; 79: 287-293.

70. Sekizaki T, et al. Endocarditis in chickens caused by subclinical infection of Streptococcus gallolyticus subsp. gallolyticus. Avian Diseases 2008; 52: 183-186. 